
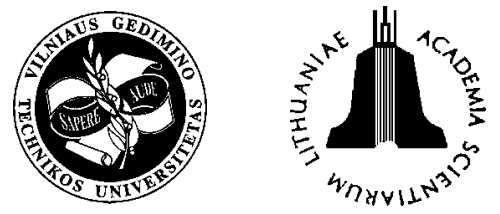

JOURNAL OF CIVIL ENGINEERING AND MANAGEMENT

http:/www.jcem.vgtu.lt

2004, Vol X, No 4, 295-302

\title{
DURABILITY OF THE PAINTED RENDERED FACADES, WHEN INTRODUCING ARTIFICIAL ACIDIC RAIN SOLUTION
}

\author{
Rosita Norvaišienė, Arūnas Burlingis, Vytautas Stankevičius \\ Laboratory of Building Thermal Physics, Institute of Architecture and Construction of Kaunas University of \\ Technology, Tunelio g. 60, LT-44405 Kaunas, Lithuania.E-mail: rosita@email.lt
}

Received 16 July 2004; accepted 18 Oct 2004

\begin{abstract}
The essential function of exterior walls is to provide a continuous barrier to the exterior environmental conditions. The decay of the building facades is accelerated by atmospheric pollution and acidic precipitation. For determining of the impact of atmospheric pollution on the building facade face materials, the tests examining the impact of the cyclic moisturing-drying have been carried out with the use of acidic water solution to imitate acidic rain. The results of the experiments demonstrated that water solutions have greater destructive effects on the paint film by penetrating through it into the plaster base, thus forming new derivatives in it, which increase water absorption in the plaster base. In order to improve the standard testing on weather resistance of facing building materials, which does not ignore the impact of the atmospheric pollution, for localities where acidic precipitations are frequent, the climatic tests should also include the deteriorating effect of acidic water solutions on facing materials. The results of the experiments will be used for a creation of the prognostic method which will lead to the establishment of a new accelerated climatic ageing test cycle meant for determining a more reliable prognosis of the durability of materials.
\end{abstract}

Keywords: weather resistance, durability, acidic precipitation, moisturing-drying tests, water absorption, carbonisation.

\section{Introduction}

This article reviews important issues in assessing the durability of rendered facade walls, focusing on the interrelation between experience, testing and modelling. The need for a prognosis of the building facade facing durability in the estimation of climatic factors came into focus with the increase of the building material variety. Durability of a material is described at times as if it were a basic property, measured as the length of time it will function adequately [1]. Degradative effects are brought about by different agents including mechanical, thermal, chemical and biological agents. In the context of the building facade ageing, the climate of Lithuania is rather severe. In the country's climatic zones, rain and fogs, freezing and thawing are rather frequent climatic factors that affect the state of facade materials thus causing their decay. It should be stressed that the material's weather resistance is, in fact, the resistance to a complex of natural agents. Mostly building facades are affected by humidity, frost, and sun radiation.

The investigation of the durability of external surfaces of enclosures, including facade paints, carried out until now, does not include all destructive climatic factors. As a rule, the cyclic climatic tests, the impact of moisturing-drying, freezing-thawing, and the ultra-violet radiation used to be estimated [1-4]. Year by year, in the climatic ageing investigations, an attempt was made to imitate a greater number of climatic factors, thus seeking to make the laboratory climatic tests more similar to the natural climatic factors that operate in natural environment, at the same time forecasting the real durability of the material more precisely.

It was found during field observations of building facades that deterioration of their surfaces is being accelerated by air pollution [5-7], which is a significant climatic factor, increasing the rapid ageing of buildings, especially the historical ones and monuments. The atmospheric pollution of a chemical origin together with precipitation penetrate the surface of enclosures and migrate into deeper layers. Because of their ability to melt in water, these admixtures together with the soluble particles of the material form new, often weakening and volumeincreasing components that get crystallised in the capillaries of the material and deteriorate it mechanically. Chemical agents in the form of moisture (liquid water and water vapour) are responsible for corrosion in metals, the efflorescence of salt compounds from porous materials, and the deterioration of concrete by the action of aqueous solutions. Acidic rain and other types of acidic precipitation, eg dew and fog, are formed when pollution particles are combined with water drops in the atmosphere. Acidic precipitation includes sulphates (50-60\%); 
nitrates $(25-30 \%)$, and chlorides (15\%). The highest acid concentration formed of atmospheric pollution occurs at the beginning of the precipitation. According to the research carried out in the USA [5], it has been determined that, when the reaction of the atmospheric precipitation does not exceed $\mathrm{pH}=4,6-4,7$, it does not cause considerable changes in constructions, therefore the amount of sulphates in the precipitation should not exceed $1,5-2 \mathrm{~g} / \mathrm{m}^{2}$ a year.

Fog water comes out to be the most acidic one $(\mathrm{pH}=2-4$, in some cases even reaching $\mathrm{pH}=1-2)$. Sulphuric and nitrogenic acids are most intensively composed at high relative air humidity and at outdoor temperature close to $0^{\circ} \mathrm{C}$.

The impact of acidic rain as an activator of metal corrosion is well known and has been exhaustively investigated [8] as well as that of atmospheric pollution on the monumental buildings and monuments constructed of stone, limestone, marble, and sandstone [5, 8-11]. It has been determined that, when $\mathrm{pH}=4,3$, concrete and metals decay [8]. Concrete and masonry are not resistant to atmospheric pollution, although the period and the degree of destruction are usually smaller than in the cases of limestone and ironful metal alloys [8-10]. Since the majority of modern building facades are made of concrete, brick, and plaster, the estimation of the impact of climatic aggressiveness on their physical, mechanical, and aesthetical properties is urgent.

Thus, the investigation of the impact of chemical reactions taking place between environmental pollution and the materials of the building facades requires exhaustive experiments. The impact of acidic rain on the facade paints should be tested on the plaster that would completely correspond to the one rendered at the building sites, because roughness of the plaster surface considerably affects the durability of the system of 'paintbasis'.

Most often, traditional standard (comparative) tests applied in durability investigation are based on the complex of extreme conditions imitating the 'universal environment' [12] and therefore are inadequate to climatic conditions of a certain locality. The achieved test results little correlate with natural reality. That is why, at present, in the Laboratory of Thermal Physics at the Institute of Architecture and Construction (Kaunas) the experiments are carried out to determine the impact of the atmospheric pollution on the facade paints.

The article presents the results of the carried out experiments that reveal the ageing characteristics of the lime-cement plaster painted with various paint covers. The research aims at the creation of the method for investigating of the building facing materials that would allow for a more precise imitation of climatic factors, including atmospheric pollution, which has not yet been considered in the climatic tests in Lithuania.

\section{Experimental section}

The facade plaster paints have been used as a decorating cover and as a layer against negative environmental effects. The paint covers should be resistant to an aggressive environment and thus protect the basis against the destructive climatic factors affecting its durability.

The facade plaster paints should well protect the plaster against rain water penetration and diminish water absorption of the painted basis. On the other hand, they should be water-vapour permeable and resistant to atmospheric pollution.

Different sorts of facade plaster paints have been selected for testing. The research aimed at the discovery of typical ageing mechanisms under different destructive climatic factors. Three paint-cover sorts have been investigated, ie water vinil-copolimeric (V), acrylic, water-dispersive modified with silicon (A); water poluretanic $(\mathrm{P})$, and plaster without a paint-cover $(\mathrm{T})$. The composite mineral plaster has been selected as a paint basis, since it is mostly used for wall finishing in Lithuanian dwelling and industrial buildings. The research has been focused on the changes that occur in an external layer of the painted plaster about $5 \mathrm{~mm}$ thick.

\subsection{The experimental method of the laboratory investigation of moisturing-drying effect}

Of all the degradative agents, moisture (atmospheric and rainfall) is particularly important to assessing the long-term performance of facade walls. Performance testing establishes the degree to which a component or assembly conforms to an acceptable level. To examine the impact of moisturing-drying the cycle was composed on the basis of earlier scientific research $[1,3,6]$ and the statistic data of the Lithuanian climate [13], with respect to the average rain duration, number of sunny days, the maximal outdoor temperatures in warm seasons, the temperature at the surface of the building wall, and relative air humidity. With the knowledge of an average chemical composition of acidic rain, the moisturing-drying cycle (further on referred to as M-D) has been worked out. During the cycle, the samples were immersed about $3 \mathrm{~mm}$ deep into the water for two hours at $20^{\circ} \mathrm{C}$ temperature, with the painted surfaces immersed to the surface of water. Then they were dried for 22 hours (4 hours at $29^{\circ} \mathrm{C}$ temperature and 18 hours at $50{ }^{\circ} \mathrm{C}$ temperature), the drying taking place only on one, ie the painted side, thus seeking to create the drying conditions close to the natural ones. The samples were painted in white colour.

Three types of the M-D cycles were worked out, ie sample-moisturing in distilled water; sample-moisturing with the water solution $\mathrm{pH}=4,5$, imitating acidic rain; moisturing with the acidic water solution $\mathrm{pH}=2,5$, imitating acidic fog. 
Acidic rain, whose average $\mathrm{pH}=4,5$ was imitated by the preparation of acidic water solution including $\mathrm{H}_{2} \mathrm{SO}_{4}$ and $\mathrm{HNO}_{3}$ acids into corresponding 2,0 mg/l and $0,54 \mathrm{mg} / \mathrm{l}$ concentrations. According to the data of 1981-1990, these are average acid concentrations in precipitation. Acidic fog was imitated by increasing the acidity of water solution of the mentioned acids up to $\mathrm{pH}=2,5$ [14].

The drying phase of the cycle was worked out with respect to the fact that the drying of the building walls is mostly conditioned by two parameters, ie outdoor temperature and relative air humidity. By the initial laboratory tests it was determined that the winds of average speed do not have a considerable impact on drying painted surfaces (Fig 1).

That is why the impact of the wind was not included into the drying phase.

The drying phase of the moisturing-drying cycle consists of two stages:

- drying at high outdoor temperatures in summer;

- drying at high outdoor temperatures in summer under direct sun radiation onto the building facade that increases the surface temperature and decreases the relative air humidity at the wall surface.
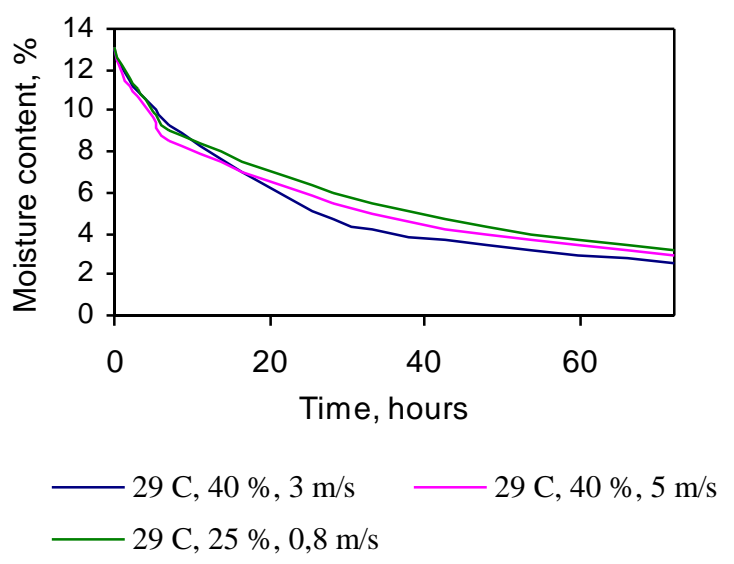

Fig 1. Drying the painted $\mathrm{V}$ samples at various wind speeds

During experiments, after every 30 M-D cycles, three samples of each type were taken out, their vapour resistance measured, the curves of water absorptivity from the surface of water and drying curves drawn (at $25^{\circ} \mathrm{C}$ and $40-50 \%$ of relative air humidity).

\subsection{Trends of water absorbtivity enlargement of the system 'basis+paint' during M-D cycling}

Water permeability of the finishing layers determines the amount of precipitation that penetrates into deeper layers thus causing the chemical pollution penetration into the material, which, in its turn, evokes chemical corrosion of the basis. Fig 2 demonstrates the water absorption values of $\mathrm{V}$ samples (after 2 hours of immersion) from the point of its moisture content after the drying phase. It is calculated by subtracting the moisture content values after drying phase from adequate values after moisturing. Having investigated water absorption values of the system 'vinil-copolymeric cover + plaster' (V) (by immersing the painted surface of $2-3 \mathrm{~mm}$ into water solution for two hours), during the M-D cycling (Fig 2), it was determined that the samples immersed in acidic water solution, whose $\mathrm{pH}=2,5$, after $100 \mathrm{M}-\mathrm{D}$ cycles, approximately absorbed a six times greater amount of water than the samples that were immersed in distilled water $(\mathrm{pH}=7)$. It follows that the impact of the fog is more intensive than that of clean rainwater.

A stronger acidic water solution has a greater effect on the paint structure and thus increases the capillary water absorption of the sample through the paint cover, since the paint looses its protective quality more rapidly.

The samples immersed in acidic water solution $(\mathrm{pH}=4,5)$ on their painted surface for two hours, after 100 M-D cycles, absorbed a twice-greater amount of water than the samples in distilled water $(\mathrm{pH}=7)$.

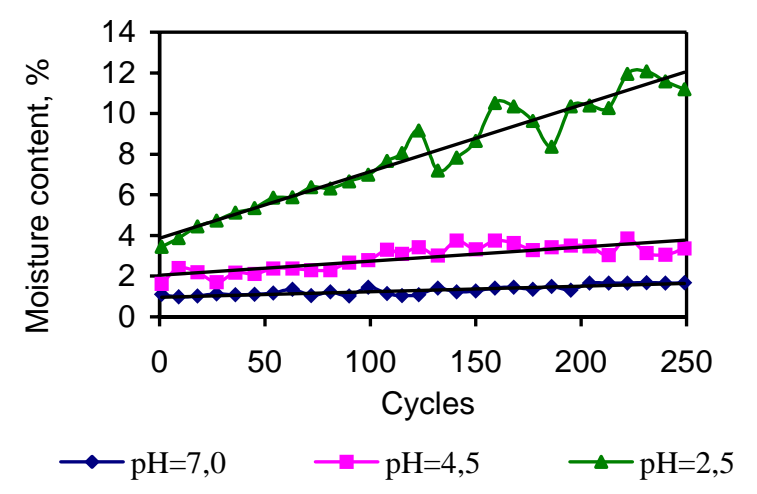

Fig 2. Change of moisture content of the $\mathrm{V}$ samples after two hours of immersion during M-D cycling

Stronger acidic water solutions deteriorate paint cover more rapidly. For instance, water solution $(\mathrm{pH}=$ 2,5 ) after the same number of the M-D cycles, increases water absorption of the samples painted with the vinilcopolimeric paints (V) for approximately 3 times, if compared to the effect of water solution whose $\mathrm{pH}=4,5$.

According to the results of the implemented M-D cycles, it can be maintained that impact after 100 cycles in solution $\mathrm{pH}=4,5$ or after 21 cycle in solution $\mathrm{pH}=2,5$ is adequate as after 200 cycles in distilled water. That was calculated by the empirically established equations, which show the change of moisture content during M-D cycling:

1) in solution $\mathrm{pH}=2,5, \omega=0,0328 \cdot c+3,858$,

2) in solution $\mathrm{pH}=4,5, \omega=0,069 \cdot c+2,048$,

3 ) in distilled water, $\omega=0,0029 \cdot c+0,953$, where $c$ - number of cycles, $\omega$ - moisture content, mass $\%$. 


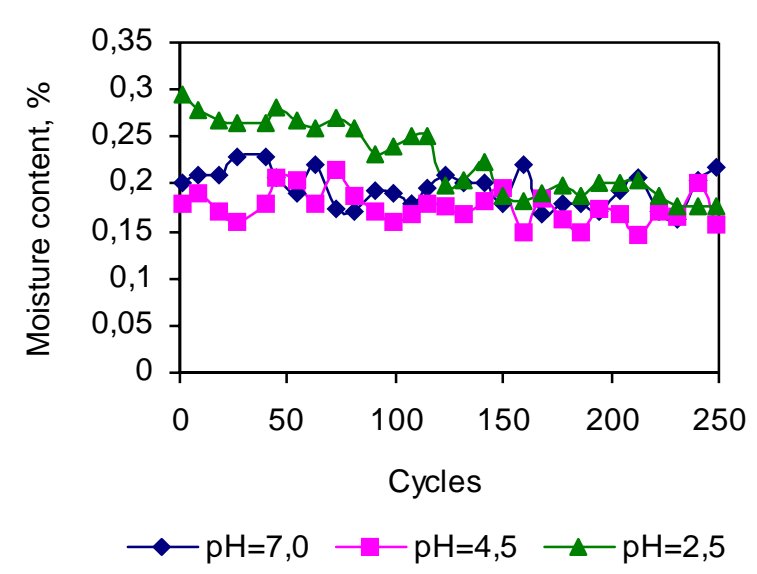

Fig 3. Change of moisture content of the A samples after two hours of immersion during M-D cycling

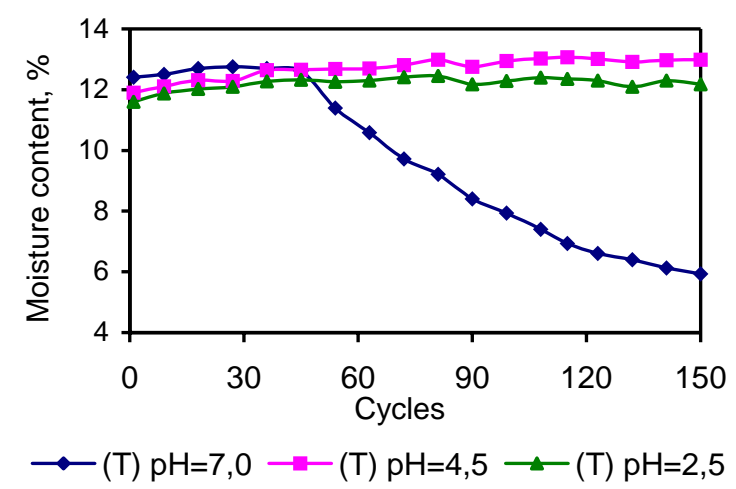

Fig 4. Water absorption of the $\mathrm{T}$ samples from water surface after two hours of immersion

The results of experiments allow to use the solution $\mathrm{pH}=2,5$ for accelerating the ageing of M-D cycling in view of the fact that moisturing is considered to be one of the main ageing factors for building facades. Water on the surface is known to be a key agent in promoting the fracturing and erosion of building envelope and coating. It penetrates the pores and cracks and causes mechanical stresses both by hydration and freezing and also by subsequent crystallisation of salts during drying.

The chemical composition of solution used in experiments is similar to acidic rainwaters in Lithuania.

The analogical ageing of the samples has been observed when treating the A samples of the system 'acrylic cover-plaster' (Fig 3). However, in this case, a very small water permeability of the acrylic cover takes place. For example, after $100 \mathrm{M}-\mathrm{D}$ cycles: in two hours it absorbs only from about $0,17 \%$ to $0,24 \%$ of water (meanwhile, the absorption of the $\mathrm{V}$ samples after $100 \mathrm{M}-\mathrm{D}$ cycles in the solution whose $\mathrm{pH}=2,5$ approaches $7 \%$ ).

For preparing of the A samples the silicon-based primer was used, as it does not allow the capillary forces of water absorption to operate by repulsing water from the painted surface. Although the A samples were obviously affected by acidic water solution, the absorption was, in fact, very small.

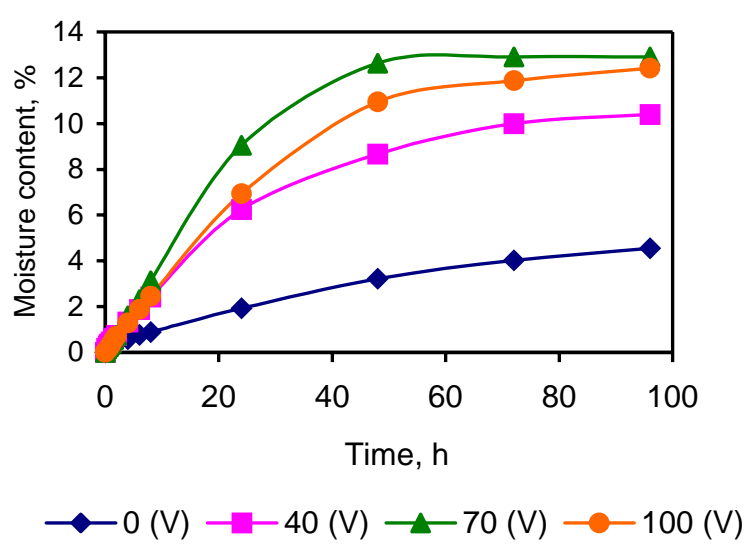

Fig 5. Water absorption rates of the $\mathrm{V}$ samples from water surface after $0,40,70,100 \mathrm{M}-\mathrm{D}$ cycling in distilled water

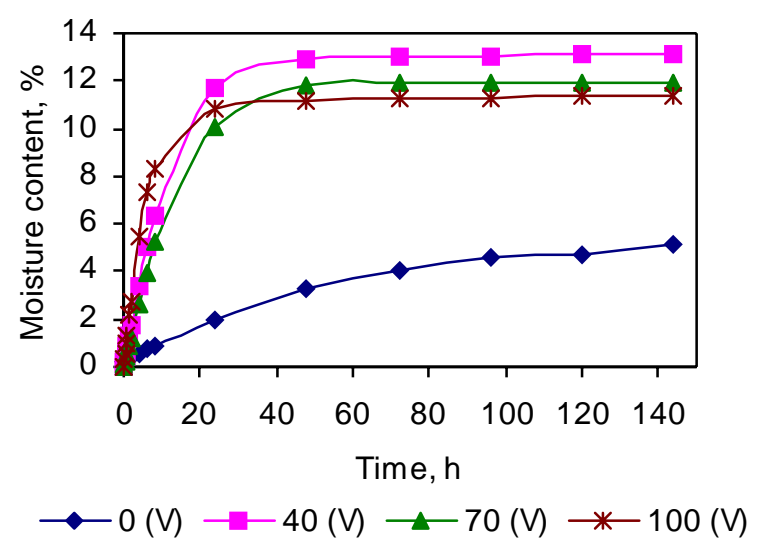

Fig 6. Water absorption rates of the $\mathrm{V}$ samples from water surface after $0,40,70,100 \mathrm{M}-\mathrm{D}$ cycling in acidic water solution $(\mathrm{pH}=4,5)$

In case of the plaster samples not painted at all $(\mathrm{T})$, when they were treated with the M-D cycles, and immersed in distilled water $(\mathrm{pH}=7,0)$, demonstrated a rather strange 'behaviour': with the increase of the M-D cycle number, the sample absorption after about $50 \mathrm{M}$ $\mathrm{D}$ cycles began to continually decrease. Meanwhile, in acidic water solutions $(\mathrm{pH}=4,5$ and $\mathrm{pH}=2,5)$, water absorption of the immersed samples after two hours practically remained stable.

The absorbtivity of the plaster samples $\mathrm{T}$ in acidic solutions fluctuates near the maximal value of the plaster water absorbtivity (Fig 4).

In order to compare the physical properties of the samples treated with various numbers of the M-D cycles as well as their physical properties changes (Figs 5-8), the curves of water absorption of unpainted and painted plaster samples from water surface after their treatment with $0,40,70$, and $100 \mathrm{M}-\mathrm{D}$ cycles in distilled and acidic water solutions $(\mathrm{pH}=4,5$ and $\mathrm{pH}=2,5)$ have been drawn.

Having analysed the curves of water absorption from water surface (Figs 5-8) and their changes after the M- 
D cycle treatment effect on the V samples (Figs 5-7), the following conclusions can be drawn:

- with the increase of the number of the M-D cycles, the protective properties of the paints become weaker. That is why the speed and the maximal value of water absorbtivity in the samples increase (Figs 5-7);

- when immersed in acidic solutions, the painted $\mathrm{V}$ samples reach their highest value of the maximal water absorbtivity (12-13\% of the mass) after 40 M-D cycles in solution $\mathrm{pH}=4,5$ and after $100 \mathrm{M}$ $\mathrm{D}$ cycles in solution $\mathrm{pH}=2,5$ (Figs 6,7);

- when immersed in distilled water, the painted V samples reach their highest value of the maximal water absorbtivity (12-13\% of the mass) after 70 M-D cycles (Fig 5);

- the lowest destructive effect of the M-D cycles on the paint covers has been observed when the samples were immersed in distilled water; the highest destructive effect has been observed when the samples were immersed in acidic water solution $(\mathrm{pH}=2,5)$ (Figs 5-7);

- when the protective properties of the paint covers grow weaker, in the composite mineral plaster the processes diminishing the maximal water absorbtivity occurs, i.e. the ability to preserve a greater amount of water in itself decreases (Figs 5-7);

- after 40 M-D cycles in acidic solutions (Figs 6, 7) and, correspondingly, after $70 \mathrm{M}-\mathrm{D}$ cycles in distilled water (Fig 5), the maximal water absorbtivity of the V samples starts decreasing because of the increasing porosity of the plaster's material caused by the washing out of the formed soluble salts as a result of the impact of acids and free lime from capillaries, and the process of carbonisation.

When analysing the curves of water absorption from water surface of the A samples (Figs 9-11) and the changes after their treatment by the M-D cycles, it has been observed that:

- during the M-D cycles, when the painted A samples are immersed in distilled water, the maximal value of absorption of the samples is diminishing: if the maximal water absorption value of untreated by the M-D cycles samples reached about $1,9 \%$ of mass, so, after $100 \mathrm{M}-\mathrm{D}$ cycles, the maximal value of the absorption of the samples decreased up to $0,8 \%$ of mass (Fig 9);

- when during the M-D cycles the samples are immersed in water solution $(\mathrm{pH}=4,5)$, the maximal water absorption of the A samples decreases quicker than in case of M-D cycles in distilled water: the maximal value of absorption of the samples untreated by the M-D cycles in the acidic water solution $(\mathrm{pH}=4,5)$ reached about $2,4 \%$ of mass, and, after $70 \mathrm{M}-\mathrm{D}$ cycles, the maximal value of absorption decreased to $0,8 \%$ of mass (Fig 10);

- the destructive effects of the M-D cycles on the A samples both in acidic water solution $(\mathrm{pH}=4,5)$

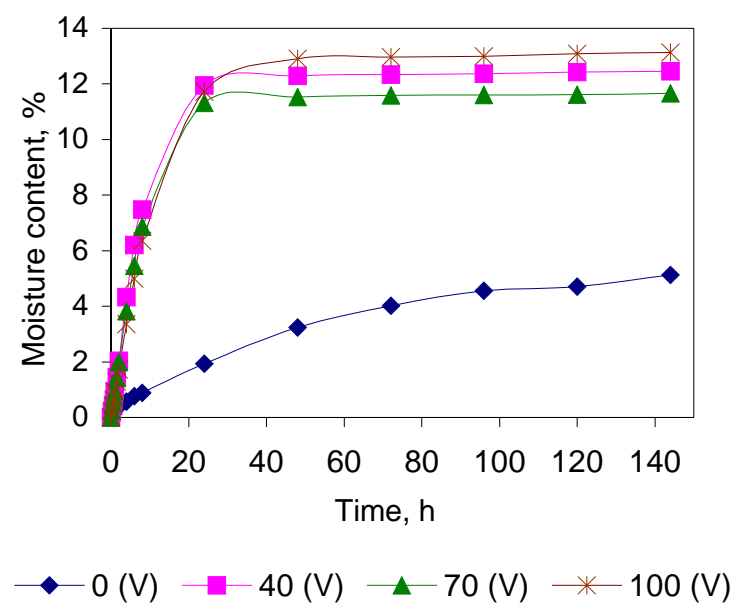

Fig 7. Water absorption rates of the $\mathrm{V}$ samples from water surface after $0,40,70,100$ M-D cycling in acidic water solution $(\mathrm{pH}=2,5)$

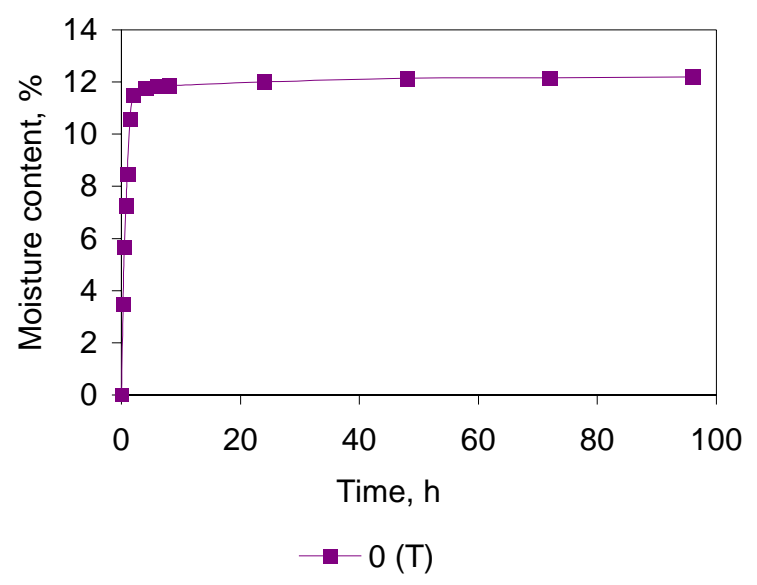

Fig 8. Water absorption rates of untreated $\mathrm{T}$ samples from water surface

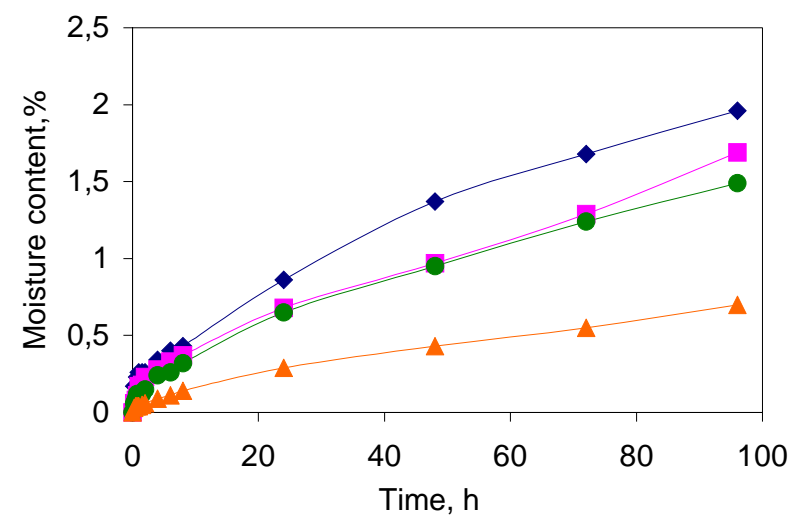

$\multimap 0(\mathrm{~A}) \longrightarrow 40(\mathrm{~A}) \longrightarrow 70(\mathrm{~A}) \multimap 100(\mathrm{~A})$

Fig 9. Water absorption rates of the A samples from water surface after $0,40,70,100$ M-D cycling in distilled water 


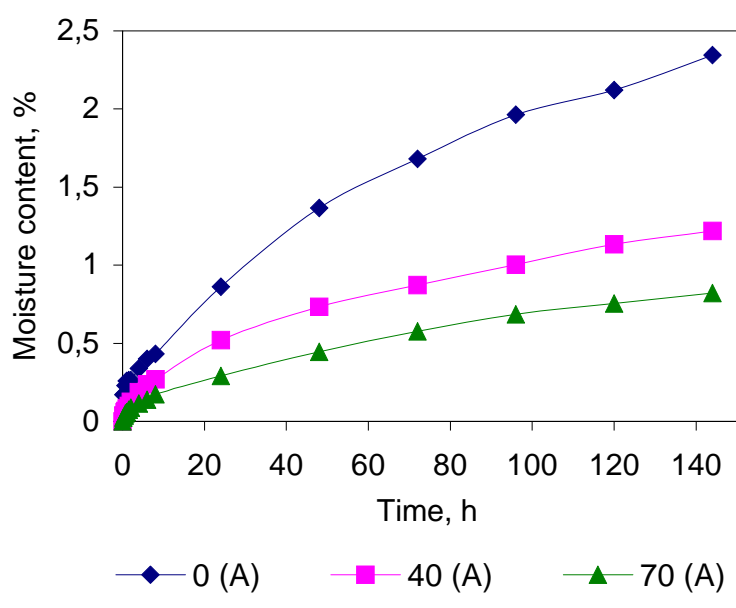

Fig 10. Water absorption rates of the A samples from water surface after $0,40,70 \mathrm{M}-\mathrm{D}$ cycling in acidic water solution $(\mathrm{pH}=4,5)$

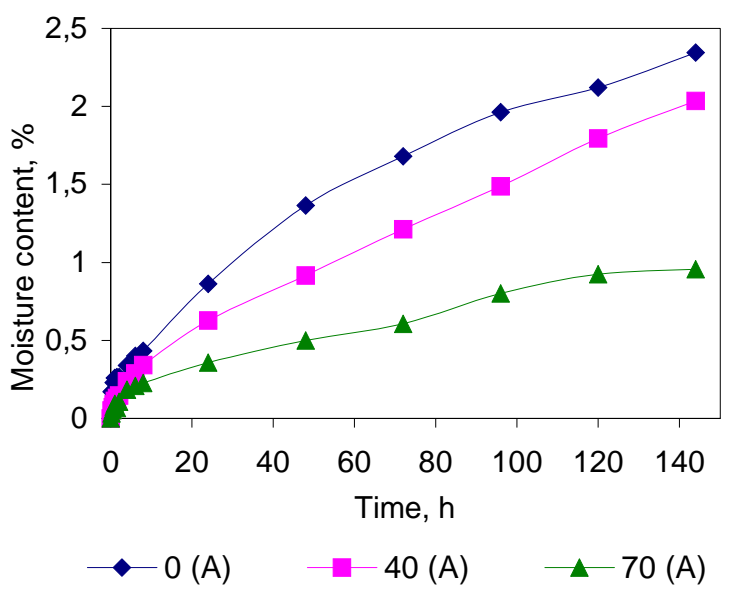

Fig 11. Water absorption rates of the A samples from water surface after 0, 40, $70 \mathrm{M}-\mathrm{D}$ cycling in acidic water solution $(\mathrm{pH}=2,5)$

and in water solution $(\mathrm{pH}=2,5)$ are identical (Figs $10,11)$

- the maximal water absorbtivity of the A samples when treated by the M-D cycles starts decreasing because of the increasing porosity in the plaster material, firstly, caused by the washing off the soluble salts composed under the impact of acids and the carbonisation of free lime and its washing off (Figs 9-11).

During the M-D cycles the carbonisation of free lime takes place in the plaster material, and free lime and other soluble compositions formed in the process, eg $\mathrm{Ca}\left(\mathrm{NO}_{3}\right)_{2}$, are washed off. All these processes enlarge the diameters of the capillaries of the material, which increases the speed of water absorbtivity but diminishes the maximal absorption value. The experiment for finding out the depth of the carbonised plaster beneath the paint layer was carried out, the sides of the samples being cut and treated with phenolphthalein solution. As the cross-section shows, the areas of the carbonised plaster are not coloured, but the areas of non-carbonised plaster are painted in a rosy colour (it is free lime that gets colored). Table presents the distance from the surface of samples to the areas of non-carbonised plaster.

The photos (Figs 12-16) show the sections of some samples treated with the phenolphthalein solution.

The depth of plaster carbonisation beneath the paint cover in the samples after 40, 70, 100 moisturing-drying cycling

\begin{tabular}{c|c|c|c}
\hline $\begin{array}{c}\text { Number of M-D } \\
\text { cycles, the type } \\
\text { of paint }\end{array}$ & $\begin{array}{c}\text { In distilled } \\
\text { water } \\
\mathrm{pH}=7,0 \\
(\mathrm{~mm})\end{array}$ & $\begin{array}{c}\text { In water } \\
\text { solution } \\
\mathrm{pH}=4,5 \\
(\mathrm{~mm})\end{array}$ & $\begin{array}{c}\text { In water } \\
\text { solution } \\
\mathrm{pH}=2,5 \\
(\mathrm{~mm})\end{array}$ \\
\hline $40(\mathrm{~V})$ & 5 & $7-8$ & 10 \\
\hline $70(\mathrm{~V})$ & n.d. & 10 & n.d. \\
\hline $100(\mathrm{~V})$ & 2 & n.d. & n.d. \\
\hline $40(\mathrm{~A})$ & 0 & 0 & 0 \\
\hline $70(\mathrm{~A})$ & n.d. & 0 & n.d. \\
\hline $100(\mathrm{~A})$ & 0 & n.d. & n.d. \\
\hline $160(\mathrm{~T})$ & all area & n.d. & 5 \\
\hline
\end{tabular}

Note: n.d. - no data.

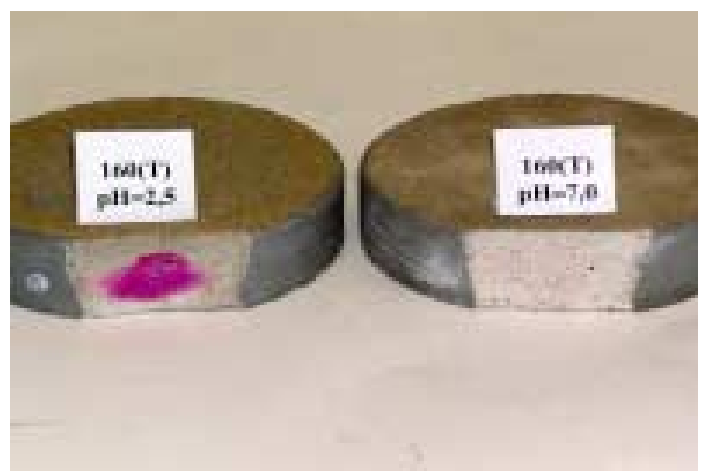

Fig 12. Carbonisation of the $T$ samples after $160 \mathrm{M}-\mathrm{D}$ cycles

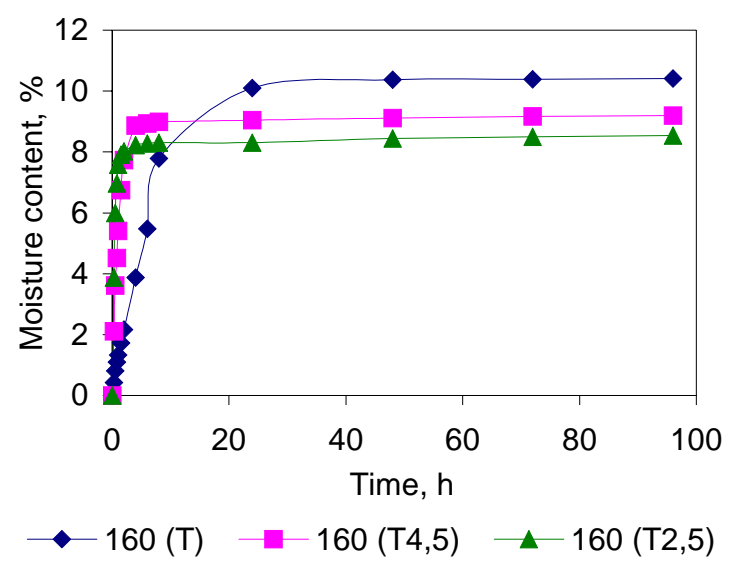

Fig 13. Water absorption of the $\mathrm{T}$ samples from water surface after 160 M-D cycling 
The photo in Fig 12 shows that the plaster got completely carbonised after $160 \mathrm{M}-\mathrm{D}$ cycles in distilled water $(\mathrm{pH}=7,0)$; meanwhile, when the samples were immersed in the solution whose $\mathrm{pH}=2,5$, after the same number of the M-D cycles only the $5 \mathrm{~mm}$ thick surface layer got carbonised; however, deeper in the sample the material remained uncarbonised.

Fig 13 demonstrates that the maximal water absorption of the $\mathrm{T}$ sample in distilled water during the M-D cycles decreases slightly (Figs 8, 13); meanwhile, the speed of water absorption of the samples immersed in water solutions whose $\mathrm{pH}=4,5$ and $\mathrm{pH}=2,5$ increases; however, at the same time their maximal value of water absorption decreases (Figs 6, 7, 13). It can be explained in the following way: free lime and the composed soluble calcium nitrate are washed off from capillaries, therefore their diameter in the uncarbonised plaster increases. Carbonisation also increases the diameter of capillaries, which accelerates water absorbtivity but weakens the capillary forces of water absorption and thus diminishes the maximal water absorption of the material.

Practically, in the plaster treated with distilled water, carbonisation and washing off of free lime take place but no soluble compositions are formed. Both processes increase the diameter of the capillaries, thus weakening the values of the capillary absorbtive forces and the maximal value of water absorption. In this case, at the initial moment, the absorbtivity should accelerate, contrariwise, it decreases (Figs 7, 13). The phenomenon might be explained exclusively by the accumulation of free lime at the external surface of the sample during its washing off, which causes the narrowing of the capillaries in the displayed area.

In the samples $\mathrm{T}$ treated with the acidic solution, the carbonisation does not occur, since in the plaster lime reacts with nitric and sulphuric acidic solutions to compose calcium nitrate and sulphatum (gypsum). Both being water soluble, especially calcium nitrate, they are washed off from the plaster capillaries. Consequently, their diameters enlarge and, at the beginning, water absorption speed accelerates but the value of maximal absorption decreases, which is caused by the weakened absorbtive forces of capillaries. The result is clearly seen by the comparison of the absorbtivity curves (Figs 8, 13).

Paint covers that diminish water absorbtivity through the painted surface slow down the processes of carbonisation and of free lime washing off, which takes place in the plaster beneath the paint cover. With acidic water solution continuous deterioration of the paint cover and the consequential weakening of its protective properties, the process of plaster carbonisation accelerates, and lime and composed soluble salts are washed off.

Figs 9-11 demonstrate that during the M-D cycling the maximal water absorption in the A samples decreases; the photo (Fig 16) shows that free lime beneath the paint is not washed off or carbonised. Actually, here the process of the capillary washing off takes place that enlarges the diameter of the capillaries. It is related to the

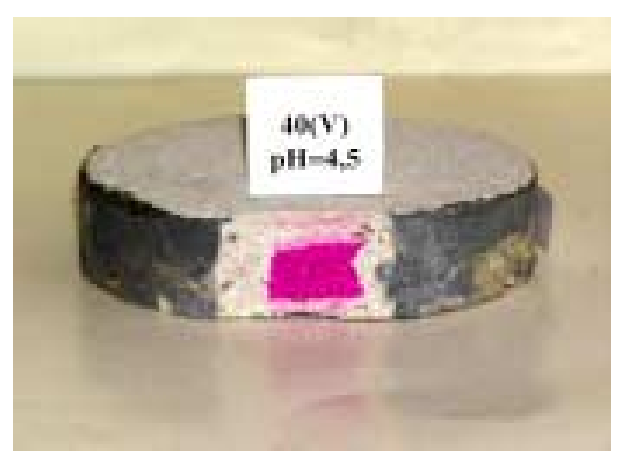

Fig 14. Carbonisation of the V sample after $40 \mathrm{M}-\mathrm{D}$ cycles in acidic $\mathrm{pH}=4,5$ solution

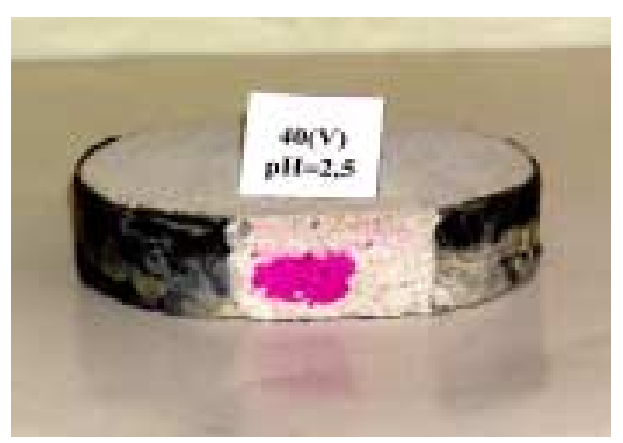

Fig 15. Carbonisation of the V sample after $40 \mathrm{M}-\mathrm{D}$ cycles in acidic $\mathrm{pH}=2,5$ solution

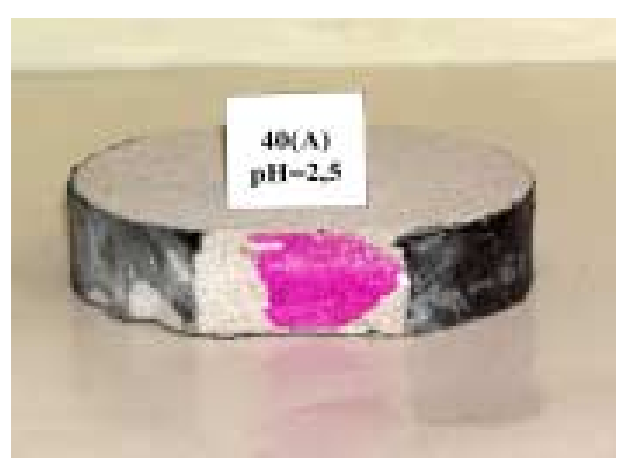

Fig 16. Carbonisation of the A sample after $40 \mathrm{M}-\mathrm{D}$ cycles in acidic $\mathrm{pH}=2,5$ solution

formation of the soluble calcium nitrate composition and its washing off.

Figs 5-7 demonstrate that during the M-D cycling the maximal water absorption value of the $\mathrm{V}$ samples as well as the speed of absorption increase at the beginning, but later (after $40 \mathrm{M}-\mathrm{D}$ cycles in acid solutions and after $70 \mathrm{M}-\mathrm{D}$ cycles in distilled water) they start decreasing. The photos (Figs 14, 15) show that after 40 M-D cycles carbonisation and lime washing off in the plaster layer beneath the paints have already begun and continuously goes deeper. Thus, the increase of water absorbtivity speed in the samples at the beginning is caused by the weakening of the protective features of 
the paints. It accelerates the process of free lime and formed compositions of soluble salts washing off from the plaster capillaries beneath the paint and carbonisation. Later on these processes start diminishing the maximal water absorption value of the sample. After some time, however, the continuing process does not affect the water absorbtive properties of the sample.

\section{Discussion and conclusions}

The investigation of ageing of building facades is the task requiring a new approach to the climatic ageing of the materials used for finishing the building facades. The durability of facing materials due to the impact of acid rains is a little analysed field in Lithuania. When modelling the environmental conditions, it is necessary to find out reasonable testing methods related to the climatic specificity of a certain locality.

Laboratory accelerated test methods always have played an important role in the assessment of materials performance, but, in general, they have not been applied by virtue of their inability to simulate and enhance the natural weathering. Tests incorporating accelerated techniques can be used when in-use conditions are known, mechanisms of deterioration are understood, key effects causing deterioration have been identified, and the range of effects (application time and severity) can be adequately simulated in a laboratory.

The experiments examining the impact of the moisturing-drying cycling when the immersed samples were in distilled $(\mathrm{pH}=7,0)$ and acidic $(\mathrm{pH}=4,5$ and 2,5 ) water solutions demonstrated that the solutions of higher acidity deteriorated the paint cover considerably, which proportionally increased the plaster's water absorbtivity. Acidic water solutions affect the plaster by penetrating through the paint cover (the more water-permeable the paint cover, the greater absorption is caused) and encourage chemical reactions in it, during which new calcium compositions are formed. With calcium nitrate and gypsum washed off, the diameters of the plaster capillaries enlarge, which accelerates water absorbtivity, but decreases the maximal value of absorption.

In order to determine the durability of the building materials used for finishing the buildings' exterior in the areas where acidic precipitation is rather frequent, the climatic tests should necessarily include the effect of artificial acidic rain solution.

The aim of our research is to improve the standard tests of the durability of facing materials as well as the methods of artificial climatic treatment.

Intermediate experimental results demonstrate the necessity to carry out a number of tests, which could help prepare the investigation methods of the ageing of the building finishing and to work out qualitative recommendations for building maintenance and protection technique.

\section{References}

1. Miniotaite, R. The durability of finishing layer external surface of building walls (Pastatų sienų dažytų paviršių ilgaamžiškumas). Monograph. Kaunas: Technologija, 2001, 75 p. (in Lithuanian).

2. Paukštys, V. Rain and wind impact on prognosis of a moisture content in exterior walls of the buildings (Lietaus ir vejo veikiamų pastatų išorinių sienų drègminès būsenos prognozavimas). Monograph. Kaunas: Technologija, 2002. 79 p. (in Lithuanian).

3. Bednar, T.; Dreyer, J. Moisture transport in masonry. Influence of different historic and modern renders on the moisture performance of walls under rain load. In: Proc of $5^{\text {th }}$ symposium on building physics in the Nordic Countries, Gothenburg, Sweden, Vol 2, 1999, p. 529-536.

4. Ramanauskas, J.; Stankevičus, V. Weather durability of thermal insulation system in external wall (Pastatu sienų šiltinimo sistemu atsparumas klimato poveikiams). Monograph. Kaunas: Technologija, 2000. 142 p. (in Lithuanian).

5. Climatic and air pollution effects on materials and equipment. CEEES WG climatic and air pollution effects. Publication No 2, 1999. 246 p.

6. Schulz, U.; Trubiroha, P.; Schernau, U.; Baumgart, H. The effects of acid rain on the appearance of automotive paint systems studied outdoors and in a new artificial weathering test. Progress in organic coatings, Vol 40, 2000, p. 151-165.

7. Boisseau, J.; Campbell, D.; Wurst, W.; Brennan, P. J. Accelerated acid etch for automotive cleacoats. In: Proc. of $1^{\text {st }}$ European weathering symposium. Prague, Czech Republic, 2003, p. 12-21.

8. Johannson, L. G. Synergistic effects of air pollutants on the atmospheric corrosion of metals and calcareous stones. Marine Chemistry, Vol 30, 1990, p. 113-122.

9. Haneef, S. J.; Dickinson, C.; Johnson, J. B. Effects of air pollution on historic buildings and monuments and the scientific basis for conservation. Corrosion and Protection Center, University of Manchester, Report on a Research Project Supported by the Commission of the European Community, 1989, p. 236-241.

10. Martinez-Ramirez, S.; Puertas, F. Behaviour of repair lime mortars by wet deposition process. Corrosion and Protection Center, (UMIST), United Kingdom, PII S00088846(97)00262-7, 1998, p. 221-229.

11. Reichert, T.; Pohsner, U. Polymer weathering: dose-response-function for material properties changed by climatic and air pollution effects. Fraunhofer Institute of Chemical Technology, ICT, 2003, p.125-134.

12. ISO, International Organization for Standardization (2000) Buildings and Constructed Assets - Service Life Planning - Part 1: General principles, ISO 15686-1.

13. RSN 156-94. Building climatology (Statybinè klimatologija). Ministry of Building and Urban Development of the Republic of Lithuania. Vilnius, 1995. 136 p. (in Lithuanian).

14. Šopauskiene, D. and Budvytyte, D. Chemical characteristics of atmospheric aerosol in rural site of Lithuania. Atmospheric Environment, Vol 28, No 7, 1994, p. 12911296. 